\title{
Canine Hypoadrenocorticism: A Bibliographic Review
}

\section{Cinthia Peres Camilo1, Mauro José Lahm Cardoso ${ }^{1,2}$, Paula Nassar De Marchi2,3, Fernando Galdino Ricci ${ }^{4}$, Murilo Sousa Romeiro ${ }^{3}$}

\author{
${ }^{1}$ Department of Veterinary Clinics, Veterinary Hospital, Londrina State University, Londrina, Brazil \\ ${ }^{2}$ Qualittas College, São Paulo, Brazil \\ ${ }^{3}$ Universidade de Sorocaba, Campus Cidade Universitária, Sorocaba, Brazil \\ ${ }^{4}$ Department of Microbiology, Center of Biological Sciences, Londrina State University, Londrina, Brazil \\ Email: maurolahm@gmail.com
}

How to cite this paper: Camilo, C.P., Cardoso, M.J.L., De Marchi, P.N., Ricci, F.G. and Romeiro, M.S. (2020) Canine Hypoadrenocorticism: A Bibliographic Review. Open Journal of Veterinary Medicine, 10, 164-172. https://doi.org/10.4236/ojvm.2020.109014

Received: August 18, 2020

Accepted: September 19, 2020

Published: September 22, 2020

Copyright (c) 2020 by author(s) and Scientific Research Publishing Inc. This work is licensed under the Creative Commons Attribution International License (CC BY 4.0).

http://creativecommons.org/licenses/by/4.0/

\begin{abstract}
Canine hypoadrenocorticism may be characterized by insufficiency of adrenocortical hormonal secretion of glucocorticoids and mineralocorticoids. Clinical signs are nonspecific such as dehydration, hypovolemic shock, bradycardia, hypotension, emesis, diarrhea, among other clinical and laboratory changes, and can mimic other diseases, and because of this, the disease can go unnoticed by the veterinarian, increasing the mortality and morbidity of patients seen in emergency consultations. Despite being of low occurrence, hypoadrenocorticism is often underdiagnosed, and should be considered in the differential diagnosis in the presence of gastrointestinal clinical signs or hypovolemic shock, and low Sodium:Potassium ratio. The definitive diagnosis is based on the dosage of cortisol before and after the application of the adrenocorticotrophic hormone. Acute treatment consists of patient stabilization, and chronic includes replacement of glucocorticoids and mineralocorticoids. Prognosis is usually favorable if the diagnosis is early and the correct treatment is performed. This article is a review focusing on clinical signs, laboratory findings, diagnosis and treatment on canine hypoadrenocorticism, to increase the knowledge about the disease to veterinarians.
\end{abstract}

\section{Keywords}

Addison, Aldosterone, Cortisol, Hyperkalemia, ACTH

\section{Introduction}

Hypoadrenocorticism is an uncommon but underdiagnosed hormonal disease as it presents findings similar to other diseases [1], and therefore it is important 
that the clinician knows it, to diagnose it early and promote a better prognosis for patients. The aim of this study was to conduct a review on canine hypoadrenocorticism.

\section{Physiology}

The adrenal gland is divided into medullary and cortex (Figure 1), which is subdivided into fasciculated, glomerulosa and reticulated zone [2]. Cortisol production occurs in fasciculated and reticulated zones, stimulated by the corticotropin releasing hormone by the hypothalamus, which stimulates pituitary and releases adrenocorticotrophic hormone (ACTH), which acts on the adrenal cortex and releases cortisol [2] [3]. Aldosterone production occurs in the glomerulosa zone, through the aldosterone angiotensin renin system [2] [4].

\section{Etiology and Pathogenesis}

Hypoadrenocorticism is divided etiologically into primary and secondary. The primary has pathogenesis centered on the gland itself and occurs when there is atrophy or destruction of the adrenal cortex, mainly by immunomediated reactions, such as autoimmune polyglandular syndromes [5] [6]. It can also be caused by inflammatory diseases, infections [4], granulomatous diseases, neoplasms, traumas, coagulopathies [2], and iatrogenic by treatment with trilostan or mitotane in dogs with hyperadrenocorticism [7], or by adrenalectomy [8]. In these cases, there is deficiency of glucocorticoids and mineralocorticoids, because the adrenal cortex is responsible for the production of theses hormones [4].

Secondary hypoadrenocorticism occurs when there is injury to the hypothalamus or pituitary gland [2] [7], with consequent decrease in adrenocorticotrophic hormone (ACTH) secretion [1], and may be caused by neoplasms [2], trauma, or iatrogenic by the use of glucocorticoids without gradual withdrawal [5]. Some authors add a division, atypical hypoadrenocorticism, whose pathogenesis is centered on the adrenal gland, equal to the primary, but there is no electrolytic alteration, because in atypical there is only glucocorticoid deficiency

[1] [9]. However, this terminology is questionable, as aldosterone secretion remains at low levels and does not differ in dogs with and without electrolytic alteration [10] [11].

Cortisol deficiency produces various effects on the body, such as hypovolemia, hypotension, absence of intestinal anti-inflammatory effect and inability to respond to stress situation, by decreasing vascular sensitivity to catecholamines [2] [3]. In addition, glucocorticoids contribute to glycogenesis and lipolysis in stressful situations and, in their deficiency hypoglycemia may occur. Meanwhile, aldosterone is important in maintaining pressure, as it acts in renal potassium excretion $(\mathrm{K})$ and distal tubular renal reabsorption of Sodium $(\mathrm{Na})$, chlorine and water, and if aldosterone deficiency occurs may be dehydration, hypotension, electrolytic disequilibrium and cardiac alterations [3] [12] (Figure 2). 


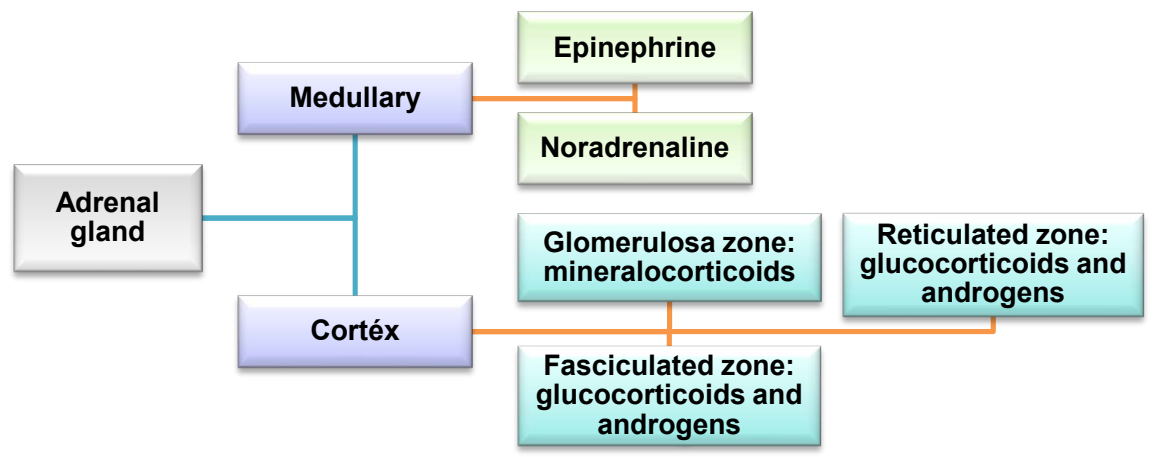

Figure 1. Anatomy and functions of the adrenal gland. Source: Adapted from Van Lanen and Sande, 2014 [2].

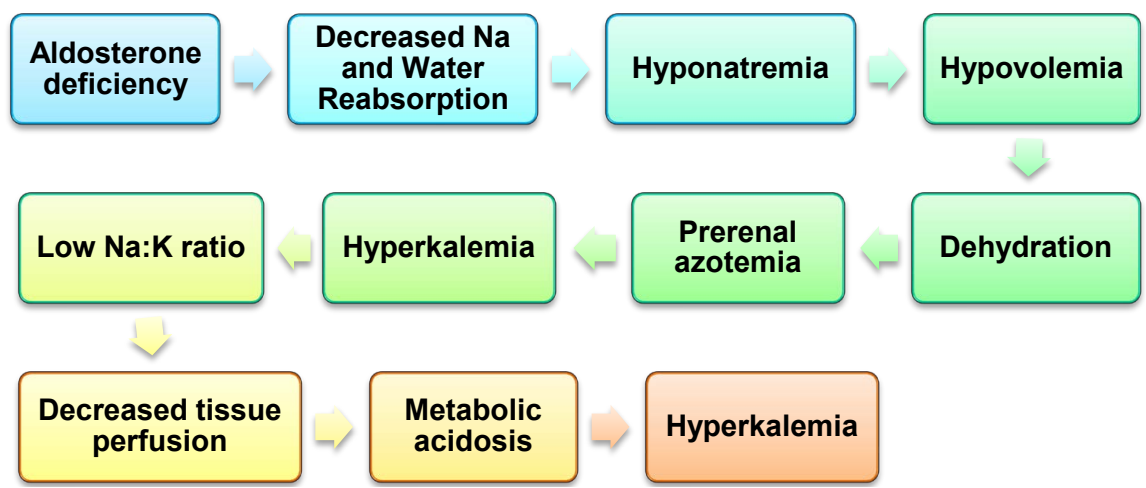

Figure 2. Decrease of aldosterone in the organism and consequences. Source: Adapted from Adler et al., 2007 [13]; Boysen, 2008 [12]; Klein and Peterson, 2010a [3]; Scott-Moncrieff, 2015 [1].

\section{Clinical and Laboratory Characteristics}

The disease can affect dogs of many ages [13], and as for sex females represent $46 \%$ [6] to $70 \%$ of cases, and males $30 \%$ [14] to $54 \%$ of cases [6]. Among the predisposed breeds are Poodle, Portuguese Water Dog [5] [6], Border Collie [5], Rottweiler, Basset Hound, West Highlander White Terrier, Great Dane, Labrador Retriever [6] and Springer Spaniel English [7].

Clinical signs may be acute or chronic and nonspecific [2] [15] as lethargy, anorexia, emesis, diarrhea, melena, abdominal pain, weight loss, weakness, polyuria and polydipsia, tremors and hair drop [3] [14]. Clinical findings and physical examination are associated with severity of disease and may range from mild dehydration to hypovolemic shock, such as weak pulse, bradycardia and hypothermia [3] [14].

In the blood count there may be anemia, usually classified as regenerative, normocytic and normochromic [16], due to bone marrow suppression due to cortisol deficiency, in addition to loss of red blood cells by gastrointestinal bleeding [1] [3]. Leukogram may evidence lymphocytosis and eosinophilia due to cortisol deficiency (Table 1), with regulates the distribution of peripheral leukocytes released under various physical, emotional and chemical stressors [16]. 
Table 1. Frequency of laboratory changes in the blood count in dogs with hypoadrenocorticism (2007-2017).

\begin{tabular}{cccccc}
\hline & \multicolumn{5}{c}{ Authors and Relative Frequencies (\%) } \\
\cline { 2 - 6 } Laboratory Alteration & $\begin{array}{c}\text { Greco } \\
2007\end{array}$ & $\begin{array}{c}\text { Klein; Peterson } \\
2010\end{array}$ & $\begin{array}{c}\text { Gunn } \text { et al. } \\
2016\end{array}$ & $\begin{array}{c}\text { Haviland } \\
\text { et al. 2016 }\end{array}$ & $\begin{array}{c}\text { Wakayama et al. } \\
2017\end{array}$ \\
\hline Anemia & 25 & $21-25$ & 25 & 16 & 28 \\
Hemoconcentration & & & 7 & 26 & \\
Eosinophilia & $13-20$ & $10-20$ & 3 & 18 & 21 \\
Lymphocytosis & 10 & $10-13$ & 2 & 12 & 33 \\
Neutrophilia & & & & 3 & 26 \\
Lymphopenia & & & 7 & 3 & 5 \\
Neutropenia & & & & 6 & 40 \\
Total dogs $\left(\mathrm{n}^{\circ}\right)$ & 225 & $\mathrm{Ni}$ & 30 & 82 & 40 \\
\hline
\end{tabular}

Legend: $\mathrm{Ni}=$ Not informed by the authors. Source: Adapted from Adler et al., 2007 [13]; Greco, 2007 [14]; Klein and Peterson, 2010a [3]; Gunn et al., 2016 [22]; Haviland et al., 2016 [6]; Wakayama et al., 2017 [10].

In biochemical tests (Table 2), there may be hypoglycemia due to cortisol deficiency, and decreased glyconeogenesis, hepatic glycogenolysis, lipolysis and glycogen storage [2] [3]. Hypoalbuminemia may occur due to low albumin synthesis by decreased nutrient intake, deficiency in absorption, liver disease or loss via gastrointestinal bleeding [1] [3]. There may also be increase in alanine aminotransferase activity (ALT) due immunomediated disease, poor perfusion and hepatic hypoxia [2] [3]. Prerenal azotemia due to poor perfusion and decreased glomerular filtration rate (GFR), dehydration and hypovolemia, and increased urea may also occur due to gastrointestinal bleeding and liver alterations [3] [7]. While hypocholesterolemia may occur due to fat absorption deficiency, low activity of the enzyme cholesterol synthase and the deficiency of the sensitive hormone lipase enzyme (LHS) in secondary hypoadrenocorticism [1].

In hemogasometry there may be acidosis, due to decreased tissue perfusion and impaired renal function, with causes increased acidic compounds in the blood, hypochloremia due to aldosterone deficiency with consequent decrease in distal tubular renal reabsorption of chorine renal and gastrointestinal losses [2] [3]. There may be Hypercalcemia due to renal excretion decreased by decreased GFR, excess intestinal and bone absorption and hemoconcentration [1] [2]. Hyperphosphatemia may occur due to dehydration and hypovolemia that cause poor renal perfusion, decreased GFR and renal phosphorus excretion [3].

Among the laboratory findings are hyponatremia and hyperkalemia, which occur due to aldosterone deficiency, with leads to decreased distal renal resorption of $\mathrm{Na}$ and renal excretion of the $\mathrm{K}$ and consequently decreased $\mathrm{Na}: \mathrm{K}$ ratio $(<30)$ [12] [13], but some dogs do not have these electrolytic changes [10] [14] [15], also called atypical hypoadrenocorticism. The normal Na:K ratio ranges from 27:1 to 40:1 [12], and in [13] the probability of diagnosis was evidenced to be confirmed in dogs with $\mathrm{Na}: \mathrm{K}$ ratio less than or equal to 24 , with $100 \%$ specificity 
Table 2. Frequency of biochemical changes and hemogasometry in dogs with hypoadrenocorticism (2007-2019).

\begin{tabular}{|c|c|c|c|c|c|c|}
\hline \multirow{2}{*}{$\begin{array}{l}\text { Laboratory } \\
\text { Alteration }\end{array}$} & \multicolumn{6}{|c|}{ Authors and Relative Frequencies (\%) } \\
\hline & $\begin{array}{c}\text { Adler } \\
\text { et al. } 2007\end{array}$ & $\begin{array}{l}\text { Greco } \\
2007\end{array}$ & $\begin{array}{c}\text { Klein; Peterson } \\
\text { 2010a }\end{array}$ & $\begin{array}{c}\text { Gunn } \\
\text { et al. } 2016\end{array}$ & $\begin{array}{l}\text { Haviland } \\
\text { et al. } 2016\end{array}$ & $\begin{array}{l}\text { Wakayama } \\
\text { et al. } 2017\end{array}$ \\
\hline Hyponatremia & 82 & 80 & 86 & 85 & 63 & \\
\hline Hyperkalemia & 85 & 95 & 95 & 59 & 76 & \\
\hline Hypochloremia & 68 & 40 & 40 & 81 & 35 & \\
\hline Hyperphosphatemia & & 85 & $66-85$ & 55 & 57 & \\
\hline Hypercalcemia & 18 & 30 & 30 & 16 & 36 & \\
\hline Acidosis & 60 & 40 & 50 & 50 & & \\
\hline Increased creatinine & & 85 & $66-95$ & 59 & 71 & \\
\hline Increased urea & & & & 66 & 83 & 10 \\
\hline Hypoglycemia & 10 & 17 & 22 & & 9 & 35 \\
\hline Hypoalbuminemia & & & $17-39$ & 7 & 26 & 87 \\
\hline Hypocholesterolemia & & & 17.5 & 22 & 29 & 76 \\
\hline Increased ALT & & 30 & $30-50$ & & & \\
\hline Total dogs $\left(\mathrm{n}^{\circ}\right)$ & 76 & 225 & $\mathrm{Ni}$ & 27 & 78 & 40 \\
\hline
\end{tabular}

Legend: $\mathrm{Ni}=$ Not informed by the authors. Source: Adapted from Adler et al., 2007 [13]; Greco, 2007 [14]; Klein and Peterson, 2010a [3]; Gunn et al., 2016 [22]; Haviland et al., 2016 [6]; Wakayama et al., 2017 [10].

and $79 \%$ sensitivity. However, in [15] a sensitivity of only $56 \%$ and specificity of $99 \%$ for the same value was detected.

\section{Diagnosis}

The diagnosis is made through history, clinical, laboratory findings and images tests, however, it is confirmed only with hormonal tests [16] [17] and ACTH stimulation test [10]. To perform the stimulation test with ACTH, the first serum sample should be collected to perform basal cortisol dosage and apply ACTH at the dose of $5 \mu \mathrm{g} / \mathrm{Kg}$, intravenously (IV) or up to $250 \mu \mathrm{g}$ per dog [14] [17]. After one hour of ACTH application, another sample is collected for post-ACTH cortisol dosage [14] [17] intramuscular administration (MI) is not indicated, as in dogs with dehydration there is decreased absorption of ACTH, may alter test results [17]. However, one study demonstrate that each deposit formulation can be administered by IM for the diagnosis of hypoadrenocorticism, and the sample can also be obtained one hour after its application [18].

A study was conducted with the dose of $1 \mu \mathrm{g} / \mathrm{Kg}$ of ACTH via IV, in dogs with hypoadrenocorticism, and the results were equivalent with the use of the standard dose of $5 \mu \mathrm{g} / \mathrm{Kg}$, witch, could reduce the cost of the diagnostic test [19]. Serum cortisol measurement can be performed by two laboratory methods, chemoluminescence immunoassay and radioimmunoassay [2] [17], with no differences between them, except where the cortisol value is less than $0.5 \mu \mathrm{g} / \mathrm{Kg}$, 
which is the detection limit of most commercial tests used for chemoluminescence [1].

The diagnosis is confirmed if the post-ACTH cortisol value is less than 2 $\mu \mathrm{g} / \mathrm{dL}$ and some authors suggest that the diagnosis can be excluded by basal cortisol dosage, because if the value is greater than $2 \mu \mathrm{g} / \mathrm{dL}$, sensitivity is $100 \%$ for the dog who not present the disease [9] [20]. However, the opposite is not valid, as there are not enough studies to prove the hypothesis that the diagnosis can be made only with the measurement of basal cortisol, and therefore, the stimulation test with ACTH should be performed to confirm the diagnosis [2] [15] [20] [21]. However, one study observed that the serum concentration of basal cortisol of $0.8 \mu \mathrm{g} / \mathrm{dL}$ would be a better predictive value of the disease (Table 3) [21], and requires further studies to analyze the predictive value of basal cortisol [2] [9] [15].

The stimulation test with ACTH does not differentiate primary hypoadrenocorticism from the secondary, and for this the serum dosage of endogenous ACTH is made [11] [12] [14] [15], however, this is a limited examination for their hormonal instability [15]. For the measurement of endogenous ACTH, a plasma sample was required, collected in a vial with the previously refrigerated and rapidly processed ethylenediaminotetraacetic acid [14] [15], and normal values correspond from 20 to $80 \mathrm{pg} / \mathrm{ml}$ [14]. The endogenous ACTH value is increased in primary hypoadrenocorticism, and in the case of secondary hypoadrenocorticism is decreased to normal [1].

\section{Treatment}

In the treatment of acute crisis, the patient is seeking to stabilization with the

Table 3. Frequency of serum basal cortisol changes in dogs with hypoadrenocorticism (2007-2019)

\begin{tabular}{ccccc}
\hline & \multicolumn{4}{c}{ Authors and Relative Frequencies (\%) } \\
\cline { 2 - 5 } Laboratory Alteration & 2007 & 2014 & et al. 2015 & 2016 \\
\hline Bennon et al. & Bovens et al. & Boretti & Gold et al. \\
Sensitivity \% & $\leq 2 \mu \mathrm{g} / \mathrm{dL}$ & $\leq 2 \mu \mathrm{g} / \mathrm{dL}$ & $\leq 2 \mu \mathrm{g} / \mathrm{dL}$ & $\leq 2 \mu \mathrm{g} / \mathrm{dL}$ \\
Specificity \% & 100 & 100 & 100 & 94 \\
Basal Cortisol & 78.2 & 63.3 & 20 & 67 \\
Sensitivity \% & $\leq 1 \mu \mathrm{g} / \mathrm{dL}$ & $\leq 1 \mu \mathrm{g} / \mathrm{dL}$ & & $\leq 0.8 \mu \mathrm{g} / \mathrm{dL}$ \\
Specificity \% & 100 & 85.7 & & 96.9 \\
Total dogs with non-adrenal \\
diseases $\left(\mathrm{n}^{\circ}\right.$ )
\end{tabular}

Source: Adapted from Lennon et al., 2007 [9]; Bovens et al., 2014 [20]; Boretti et al., 2015 [15]; Gold et al., $2016[21]$. 
correction of hydroelectrolytic disorders, which involves the performance of fluid therapy with physiological solution [2] [8] [12] [22]. After correction of dehydration it may be necessary blood transfusion, according to the degree of anemia of the patient [1]. In case of hypoglycaemia, $50 \%$ glucose replacement should be performed in dose of $0.5-1 \mathrm{ml} / \mathrm{Kg}$ IV [7] [8] [12], with diluted and low administration [12].

Correction of hyperkalemia can be performed only with fluid therapy, which leads to increased excretion of $\mathrm{K}$ by increasing GFR, or with glucose supplementation in fluid therapy [1] [7] [12]. For correction of bradycardia and in severe cases of arrhythmias resulting from hyperkalemia, $10 \%$ calcium gluconate can be used at dose of $0.5-1 \mathrm{ml} / \mathrm{Kg}$ IV slow, but does not correct the cause, which is hyperkalemia [8] [12], and electrocardiography monitoring should be done [1].

Glucocorticoid supplementation assists in improving vascular, gastrointestinal integrity, blood pressure maintenance, blood glucose and volemia [1] [17]. Corticosteroid therapy should be performed in Addisonian crisis only with dexamethasone at a dose of $0.5-4 \mathrm{mg} / \mathrm{Kg}$ IV once a day (SID) or twice a day (IDB) [12] [17], as it does not cause interference in the result of the ACTH stimulation test [1] [17].

Glucocorticoids can alter the results of the ACTH stimulation test in any formulation, and use of hydrocortisone, prednisone and prednisolone [17] should be avoided. If the test has already been performed, hydrocortisone can be used at dose $5 \mathrm{mg} / \mathrm{Kg}$, IV every 6 hours [17], or in continuous infusion $(0.5-0.625$ $\mathrm{mg} / \mathrm{Kg} /$ hour) [22].

Chronic treatment is based on the replacement of glucocorticoids and mineralocorticoids, and the replacement of glucocorticoids can be done with prednisone $(0.2 \mathrm{mg} / \mathrm{Kg} \mathrm{SID})$, which in some cases can be gradually removed, according to the maintenance of the normal Na:K ratio [1] [2]. However, prednisone should be used in stressful situations and the dose can be increased to avoid Addisonian crisis [1] [2]. Mineralocorticoid replacement should be performed with fludrocortisone (0.01- $0.02 \mathrm{mg} / \mathrm{Kg}$ IDB), or with deoxycorticosterone pivalate (2 $\mathrm{mg} / \mathrm{Kg}$ ) [2] [23], IM every 25 or 30 days [12].

The patient must be monitored by measuring electrolytes and the Na:K ratio, and also by performing laboratory tests such as urinalysis, glycemia, triglycerides and fasting cholesterol, to ascertain the presence of hyperlipidemia and diabetes, complications of continuous administrations of glucocorticoids [1] [23]. Prognosis is good when the correct treatment is performed quickly [17], but is of harm to reserved when the disease is caused by neoplasms or granulomatous diseases [1].

\section{Concluding Remarks}

Hypoadrenocorticism is an uncommon and underdiagnosed disease due to failure to perform laboratory tests to measure electrolytes and calculate the $\mathrm{Na}: \mathrm{K}$ 
ratio, and because the disease is not considered in the differential diagnosis in the clinical routine. Therefore, the electrolyte dosage should be performed, since it is a useful test for the suspicion of the diagnosis of primary hypoadrenocorticism, since the Na:K ratio below the reference value is an important indicator for the diagnosis of the disease in dogs with compatible clinical signs.

Hypoadrenocorticism should be included in the list of differential diagnoses for dogs with clinical signs, such as apathy, emesis, diarrhea, weakness, anorexia, tremor, syncope and seizure, with findings on physical examination like dehydration, hypotension and bradycardia, and laboratory alterations such as hypoglycemia, hypoalbuminemia, hyponatremia, hyperkalemia, Na:K ratio below 27 , azotemia, hypocholesterolemia, hypochloremia, lymphocytosis, anemia, eosinophilia and acidosis.

\section{Conflicts of Interest}

The authors declare that there is no conflict of interest.

\section{References}

[1] Scott-Moncrieffa J.C. (2015) Hypoadrenocorticism. In: Feldman, E.C., Nelson, R.W., Reusch, C.E., Scott-Moncrieff, J.C. and Behrend, E.N., Eds., Canine and $\mathrm{Fe}-$ line Endocrinology, 4th Edition, Elsevier Saunders, St. Louis, 485-520. https://doi.org/10.1016/B978-1-4557-4456-5.00012-2

[2] Van Lanen, K. and Sande, A. (2014) Canine hypoadrenocorticism: Pathogenesis, Diagnosis and Treatment. Topics in Companion Animal Medicine, 29, 88-95. https://doi.org/10.1053/j.tcam.2014.10.001

[3] Klein, S.C. and Peterson, M.E. (2010) Canine Hypoadrenocorticism: Part I. The Canadian Veterinary Journal, 51, 63-69.

[4] Baumstark, M.E., Sieber-Ruckstuhl, N.S., Muller, C., Wenger, M., Boretti, F.S. and Reusch, C.E. (2014) Evaluation of Aldosterone Concentrations in Dogs with Hypoadrenocorticism. Journal of Veterinary Internal Medicine, 28, 154-159. https://doi.org/10.1111/jvim.12243

[5] Hanson, J.M., Tengvall, K. and Bonett, B.N, Hedhammar, A. (2016) Naturally Occurring Adrenocortical Insufficiency: An Epidemiological Study Based on a Swedish-Insured Dog Population. Journal of Veterinary Internal Medicine, 30, 76-84. https://doi.org/10.1111/jvim.13815

[6] Haviland, R.L., Toaff-Rosenstein, R.L., Reeves, M.P. and Littman, M.P. (2016) Clinical Features of Hypoadrenocorticism in Soft-Coated Wheaten Terrier Dogs: 82 Cases (1979-2013). The Canadian Veterinary Journal, 57, 387-394.

[7] Koenig, A. (2013) Endocrine Emergencies in Dogs and Cats. Veterinary Clinics of North America: Small Animal Practice, 43, 881-886. https://doi.org/10.1016/j.cvsm.2013.03.004

[8] Meeking, S. (2007) Treatment of Acute Adrenal Insufficiency. Clinical Techniques in Small Animal Practice, 22, 46-39. https://doi.org/10.1053/j.ctsap.2007.02.006

[9] Lennon, E.M., Boyle, T.E., Hutchins, R.G., Friedenthal, A., Correa, M.T., Bissett, S.A., Moses, L.S., Papich, M.G. and Birkenheuer, A.J. (2007) Use of Basal Serum or Plasma Cortisol Concentrations to Rule out a Diagnosis of Hypoadrenocorticism in Dogs 123 Cases (2000-2005) Journal of the American Veterinary Medical Association. 231, 413-416. https://doi.org/10.2460/javma.231.3.413 
[10] Wakayama, J.A., Furrow, E., Merkel, L.K. and Armstrong, P.J. (2017) A Retrospective Study of Dogs with Atypical Hypoadrenocorticism: A Diagnostic Cut-Off or continuum? Journal of Small Animal Practice, 58, 365-371. https://doi.org/10.1111/jsap.12649

[11] Shiel, R.E. and Mooney, C.T. (2019) Redefining the Paradigm of Atypical Hypoadrenocorticism in Dogs. Companion Animal, 24, 132-140. https://doi.org/10.12968/coan.2019.24.3.132

[12] Boysen, S.R. (2008) Fluid and Electrolyte Therapy in Endocrine Disorders: Diabetes Mellitus and Hypoadrenocorticism. Veterinary Clinics of North America: Small Animal Practice, 38, 699-717. https://doi.org/10.1016/j.cvsm.2008.01.001

[13] Adler, J.A., Kenneth, J.D. and Hess, R.S. (2007) Abnormalities of Serum Electrolyte Concentrations in Dogs with Hypoadrenocorticism. Journal of Veterinary Internal Medicine, 21, 1168-1173. https://doi.org/10.1111/j.1939-1676.2007.tb01933.x

[14] Greco, D.S. (2007) Hypoadrenocorticism in Small Animals. Clinical Techniques in Small Animal Practice, 22, 32-35. https://doi.org/10.1053/j.ctsap.2007.02.005

[15] Boretti, F.S., Meyer, F., Burkhardt, W.A., Riond, B., Hoffman-Lehmann, R., Reusch, C.E. and Sieber-Ruckstuhl, N.S. (2015) Evaluation of the Cortisol-to-ACTH Ratio in Dogs with Hypoadrenocorticism and in Healthy Dogs. Journal of Veterinary Internal Medicine, 29, 1335-1341. https://doi.org/10.1111/jvim.13593

[16] Spence, S., Gunn, E. and Ramsey, I. (2018) Diagnosis and Treatment of Canine Hypoadrenocorticism. In Practice, 40, 281-290. https://doi.org/10.1136/inp.k3311

[17] Klein, S.C. and Peterson, M.E. (2010) Canine Hypoadrenocorticism: Part II. The Canadian Veterinary Journal, 21, 179-184.

[18] Sieber Ruckstuhl, N.S., Burkhardt, W.A., Hofer-Inteworm, N., Riond, B., Rast, T.T., Hofmann-Lehmann, R., Reusch, C.E. and Boretti, F.S. (2015) Cortisol Response in Heathy and Diseased Dogs after Stimulation with a Depot Formulation of Synthetic ACTH. Journal of Veterinary Internal Medicine, 29, 1541-1546. https://doi.org/10.1111/jvim.13641

[19] Botsford, A., Behrend, E.M., Kemppainen, R.J., Gaillard, P.R., Oprandy, F. and Lee, H.P. (2018) Low-dose ACTH Stimulation Testing in Dogs Suspected of Hypoadrenocorticism. Journal of Veterinary Internal Medicine, 32, 1886-1890. https://doi.org/10.1111/jvim.15256

[20] Bovens, C., Tennant, K., Reeve, J. and Murphy, K.F. (2014) Basal Serum Cortisol Concentration as a Screening Test for Hypoadrenocorticism in Dogs. Journal of Veterinary Internal Medicine, 28, 154-1545. https://doi.org/10.1111/jvim.12415

[21] Gold, A.J., Langlois, D.K. and Refsal, K.R. (2016) Evaluation of Basal Serum or Plasma Cortisol Concentration for the Diagnosis of Hypoadrenocorticism in Dogs. Journal of Veterinary Internal Medicine, 30, 1798-1805. https://doi.org/10.1111/jvim.14589

[22] Gunn, E., Shiel, R.E. and Mooney, C.T. (2016) Hydrocortisone in the Management of Acute Hypoadrenocorticism in Dogs: A Retrospective Series of 30 Cases. Journal of Small Animal Practice, 57, 227-233. https://doi.org/10.1111/jsap.12473

[23] Baumstark, M.E., Nussberger, J., Boretti, F.S., Baumstark, M.W., Riond, B., Reusch C.E. and Sieber-Ruckstuhl, N.S. (2014) Use of Plasma Renin Activity to Monitor Mineralocorticoid Treatment in Dogs with Primary Hypoadrenocorticism: Desoxycorticosterone versus Fludrocortisone. Journal of Veterinary Internal Medicine, 28, 1471-1478. https://doi.org/10.1111/jvim.12426 